\title{
Secondary conditions in adolescents and young adults (AYA) with spina bifida (SB) in Four US Programs
}

\author{
Timothy J Brei ${ }^{1 *}$, Kathleen J Sawin ${ }^{2}$, Constance Buran ${ }^{3}$, Thomas Webb ${ }^{4}$, Susan E Cashin ${ }^{5}$, Amy Heffelfinger ${ }^{6}$ \\ From 54th Annual Meeting of the Society for Research into Hydrocephalus and Spina Bifida \\ Vancouver, Canada. 7-10 July 2010
}

\section{Background}

Spina bifida affects one out of every 1200 to 1400 live births each year in the United States. Secondary conditions related to the level of the SB lesion (LOL) such as incontinence, skin breakdown, obesity, pain, and orthopedic problems (e.g., scoliosis) are common. The purpose of this presentation is to address the following questions: 1) What is the frequency of key secondary conditions (bowel/bladder status, skin breakdown, UTIs, pain, overweight, scoliosis, latex allergy)? 2) Are select secondary conditions related to LOL, school, peer or employment activities? 3) How satisfied are participants with their bowel/bladder program and is satisfaction related to clinical variables?

\section{Materials and methods}

134 parents/ youth pairs from 4 clinical programs participated in telephone interviews. Data were collected using parent and youth "Demographic and Clinical Information Form" (DCIF), the Functional Independence Measure (FIM $\left.{ }^{\mathrm{m}}\right)$, and review of the medical records.

\section{Results}

The parent sample was predominantly Caucasian. $62 \%$ had private insurance, with $28 \%$ reporting Medicaid and $11 \%$ reporting SSI for secondary income and $50 \%$ had an annual income of $\$ 50,000$ or more. AYA were aged $12-25, \mathrm{M}=15.5$ ( $\mathrm{SD}=3.24)$, $48 \%$ were male. $\mathrm{LOL}$ was: $32 \%$ thoracic/high lumbar, 25\% lumbar, $14 \%$ lumbar/ sacral and $9 \%$ other or unclear. $40 \%$ of AYA walked with or without crutches, $7 \%$ walked and used a

\footnotetext{
* Correspondence: tbrei@iupui.edu

'School of Medicine, Developmental Medicine Department, Indiana University, Indianapolis, USA

Full list of author information is available at the end of the article
}

wheelchair for sports/distance, $42 \%$ used a manual chair and $11 \%$ used a power chair for ambulation. Eightyseven percent of the AYA had a shunt with a mean revision rate $=2.63$, range $(0-15) ; 37 \%$ were hospitalized in the last year. A substantial number of participants reported secondary conditions in the past year: skin breakdown (43\%); overweight (37\%), pain (47\%); or scoliosis (40\%). 64\% had UTIs in past 3 years. $19-41 \%$ of participants reported these secondary conditions interfered with school, job or recreation with pain having the highest interference and overweight the least. The average AYA needs some assistance with bladder/bowel program and has accidents (1-2 or less a month). Parent and AYA satisfaction with bladder program was not associated with amount of assistance needed nor LOL but was related to number of bladder accidents $(r=.39$; .29 respectively). The same pattern was found with satisfaction with bowel program.

\section{Conclusions}

Parents report a substantial number of AYA with at least one secondary condition. Pain appears to interfere most with activities and overweight the least. Prevention and effective treatment of secondary physical conditions are important for full participation in society.

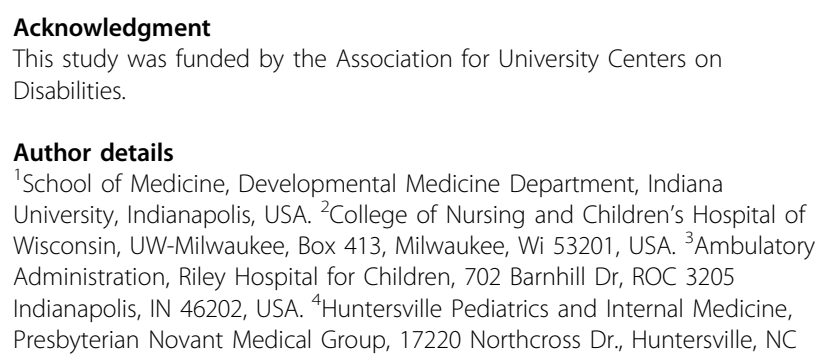

\section{Author details}

${ }^{1}$ School of Medicine, Developmental Medicine Department, Indiana University, Indianapolis, USA. ${ }^{2}$ College of Nursing and Children's Hospital of Wisconsin, UW-Milwaukee, Box 413, Milwaukee, Wi 53201, USA. ${ }^{3}$ Ambulatory Administration, Riley Hospital for Children, 702 Barnhill Dr, ROC 3205 Indianapolis, IN 46202, USA. ${ }^{4}$ Huntersville Pediatrics and Internal Medicine, Presbyterian Novant Medical Group, 17220 Northcross Dr., Huntersville, NC

(c) 2010 Brei et al; licensee BioMed Central Ltd. This is an open access article distributed under the terms of the Creative Commons Attribution License (http://creativecommons.org/licenses/by/2.0), which permits unrestricted use, distribution, and reproduction in any medium, provided the original work is properly cited. 
28036, USA. ${ }^{5}$ College of Health Sciences, University of Wisconsin-Milwaukee, Box 413, Milwaukee, USA. ${ }^{6}$ Department of Neurology, Division of

Neuropsychology, Medical College of Wisconsin, 9200 W. Wisconsin, Ave, Milwaukee, Wi 53226-3596, USA.

Published: 15 December 2010

doi:10.1186/1743-8454-7-S1-S22

Cite this article as: Brei et al:. Secondary conditions in adolescents and young adults (AYA) with spina bifida (SB) in Four US Programs.

Cerebrospinal Fluid Research 2010 7(Suppl 1):S22.

Submit your next manuscript to BioMed Central and take full advantage of:

- Convenient online submission

- Thorough peer review

- No space constraints or color figure charges

- Immediate publication on acceptance

- Inclusion in PubMed, CAS, Scopus and Google Scholar

- Research which is freely available for redistribution

Submit your manuscript at www.biomedcentral.com/submit
C Biomed Central 